\title{
CLINICAL AND ENDOSCOPIC MANIFESTATIONS OF GASTROINTESTINAL AMYLOIDOSIS: A CASE SERIES
} ANDREE HERMES KOOP, OMAR Y MOUSA, MING-HSI WANG

\author{
Gastroenterology and Hepatology Department, Mayo Clinic Florida, United States
}

\begin{abstract}
Gastrointestinal (GI) amyloidosis is rare and has varying clinical and endoscopic presentations. In this case series, we present three patients with primary systemic amyloid-light chain (AL) amyloidosis with GI involvement and complications of GI bleeding. We also provide a brief review of the literature, including clinical presentation, endoscopic findings, pathology, and management of GI amyloidosis. The endoscopic findings of GI amyloidosis can vary, including friable mucosa with erosions, ulcers, and submucosal hematomas or mucosal thickening with polypoid protrusions. The endoscopic findings may correlate with the pathologic deposition of amyloid fibrils. Treatment of GI amyloidosis is generally focused on management of the underlying condition and supportive care. Gastroenterologists should be familiar with the endoscopic findings as they may be the first suggestion of disease and allow for definitive diagnosis.
\end{abstract}

Keywords: amyloid, amyloidosis, gastrointestinal hemorrhage

\section{Introduction}

Gastrointestinal (GI) amyloidosis with both symptoms and biopsy-proven involvement of the intestinal tissue is uncommon, although GI-related symptoms are reported variably in primary (AL) amyloidosis (8\%-60\%) and secondary amyloid A (AA) amyloidosis (10\%-70\%) $[1,2]$. We present a case series of 3 patients with primary systemic AL amyloidosis with GI involvement and bleeding. Following the case presentation, we provide a review of GI amyloidosis, including clinical presentation, endoscopic findings, pathology, and treatment.

\section{Case Series}

Patient characteristics for cases 1,2, and 3 are listed in Table 1.

\section{Case 1}

A 53-year-old man was evaluated for exertional shortness of breath, and cardiac magnetic resonance imaging was suspicious for cardiac amyloidosis. A fat aspirate confirmed AL $\lambda$ amyloidosis, and a bone marrow biopsy showed $7 \%$ atypical plasma cells. The patient underwent autologous stem cell transplantation for AL amyloidosis with complete remission. Six years later, he developed symptoms of constipation and neuropathy. Esophagogastroduodenoscopy (EGD) revealed erythematous mucosa in the gastric antrum, with amyloid deposition on pathology. Fat aspirate and bone marrow biopsy also revealed amyloid involvement concerning for disease relapse, with 5\% plasma cells in the

Manuscript received: 20.12.2017

Received in revised form: 06.06 .2018

Accepted: 20.06.2018

Address for correspondence: koop.andree@mayo.edu bone marrow. He underwent a second autologous stem cell transplant with melphalan therapy.

Two weeks after repeat transplantation, the patient developed acute abdominal pain and diarrhea. White blood cell count was 19,000 cells/L. Computed tomography imaging of the abdomen revealed pancolitis; testing for Clostridium dificile was negative. Flexible sigmoidoscopy showed severe colitis with diffuse mucosal ulceration (Figure 1). Immunostaining was negative for cytomegalovirus, and pathology was positive for amyloid deposition. He was treated with a 7-day course of oral budesonide and required total parenteral nutrition for one week, after which, his symptoms improved and his diet was advanced. He had clinical remission of amyloidosis on bone marrow biopsy 3 months following autologous stem cell transplantation, with resolution of abdominal pain and diarrhea.

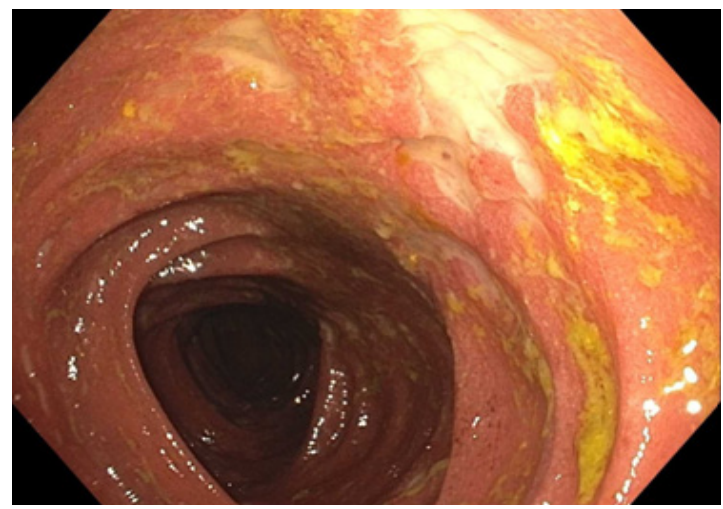

Figure 1. Sigmoidoscopy showing severe colitis with diffuse mucosal ulcerations in the whole examined colon. 
Table 1.

\begin{tabular}{|c|c|c|c|c|c|}
\hline $\begin{array}{l}\text { Case \#, Age } \\
\text { and Gender }\end{array}$ & $\begin{array}{l}\text { Time to detection of } \\
\text { GI Amyloidosis }\end{array}$ & $\begin{array}{l}\text { Gastrointestinal } \\
\text { symptoms }\end{array}$ & Endoscopic findings & $\begin{array}{l}\text { Pathology from } \\
\text { endoscopic biopsy }\end{array}$ & $\begin{array}{l}\text { Management of GI } \\
\text { manifestations }\end{array}$ \\
\hline $\begin{array}{l}\# 1 \\
53 \mathrm{M}\end{array}$ & $\begin{array}{l}6 \text { years after } \\
\text { diagnosis of systemic } \\
\text { amyloidosis }\end{array}$ & $\begin{array}{l}\text { Acute abdominal } \\
\text { pain and diarrhea }\end{array}$ & $\begin{array}{l}\text { Sigmoidoscopy; severe } \\
\text { colitis with diffuse mucosal } \\
\text { ulceration }\end{array}$ & \begin{tabular}{|l|} 
Severe active colitis \\
with focal vascular \\
amyloidosis, \\
Negative for CMV \\
Reactive and erosive \\
gastropathy
\end{tabular} & $\begin{array}{l}\text { Symptoms subsided after } \\
\text { second ASCT }\end{array}$ \\
\hline $\begin{array}{l}\# 2 \\
74 \mathrm{~F}\end{array}$ & $\begin{array}{l}\text { Time of diagnosis of } \\
\text { systemic amyloidosis }\end{array}$ & $\begin{array}{l}\text { Nausea and } \\
\text { vomiting, upper } \\
\text { GI bleeding }\end{array}$ & $\begin{array}{l}\text { Colonoscopy; large polyp in } \\
\text { the sigmoid colon } \\
\text { EGD; granular gastric } \\
\text { mucosa, erythema and } \\
\text { edema of the gastric antrum, } \\
\text { pylorus, and duodenal } \\
\text { bulb with gastric outlet } \\
\text { obstruction }\end{array}$ & \begin{tabular}{|l|}
$\begin{array}{l}\text { Tubulovillus } \\
\text { adenoma and colonic } \\
\text { amyloidosis }\end{array}$ \\
Chronic active \\
gastritis, gastric \\
and duodenal \\
amyloidosis
\end{tabular} & $\begin{array}{l}\text { Anti-nausea medications, } \\
\text { hospice care }\end{array}$ \\
\hline $\begin{array}{l}\# 3 \\
72 \mathrm{M}\end{array}$ & $\begin{array}{l}9 \text { years after } \\
\text { diagnosis of systemic } \\
\text { amyloidosis } \\
\end{array}$ & $\begin{array}{l}\text { Recurrent GI } \\
\text { bleeding with } \\
\text { melena } \\
\end{array}$ & $\begin{array}{l}\text { EGD; severe erythematous, } \\
\text { friable gastric and duodenal } \\
\text { mucosa }\end{array}$ & $\begin{array}{l}\text { Chronic } \\
\text { inflammation with } \\
\text { amyloidosis } \\
\end{array}$ & $\begin{array}{l}\text { Red blood cell transfusion, } \\
\text { proton pump inhibitor, } \\
\text { aminocaproic acid }\end{array}$ \\
\hline
\end{tabular}

\section{Case 2}

A 74-year-old woman presented to her primary care physician with fatigue, 20-pound weight loss, and irondeficiency anemia. A colonoscopy revealed a large sigmoid mass, and pathology demonstrated a tubulovillous adenoma with amyloid deposition. Bone marrow biopsy confirmed AL $\kappa$ amyloidosis with Waldenström (No 's per Dorland's and AMA.) macroglobulinemia. An echocardiogram was suspicious for cardiac involvement of amyloidosis. The patient was started on treatment with ibrutinib; however, she developed early satiety, nausea and coffee grounds emesis two weeks later. EGD revealed diffuse, friable, edematous, polypoid protrusion of the duodenal mucosa with gastric outlet obstruction (Figure 2); biopsy confirmed AL amyloidosis (Figure $3 a$ and $3 b$ ). She was initially managed with a nasogastric tube and anti-emetics. Given her poor clinical condition and prognosis she was referred to hospice care and expired 5 months later.

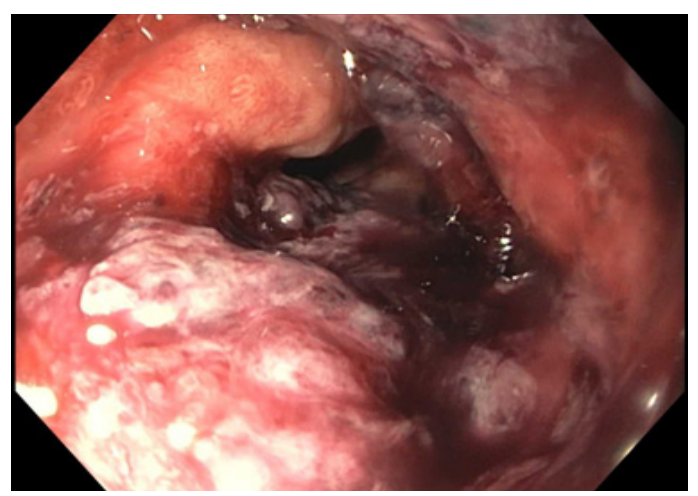

Figure 2. EGD showing friable, polypoid protrusion of the duodenal mucosa.
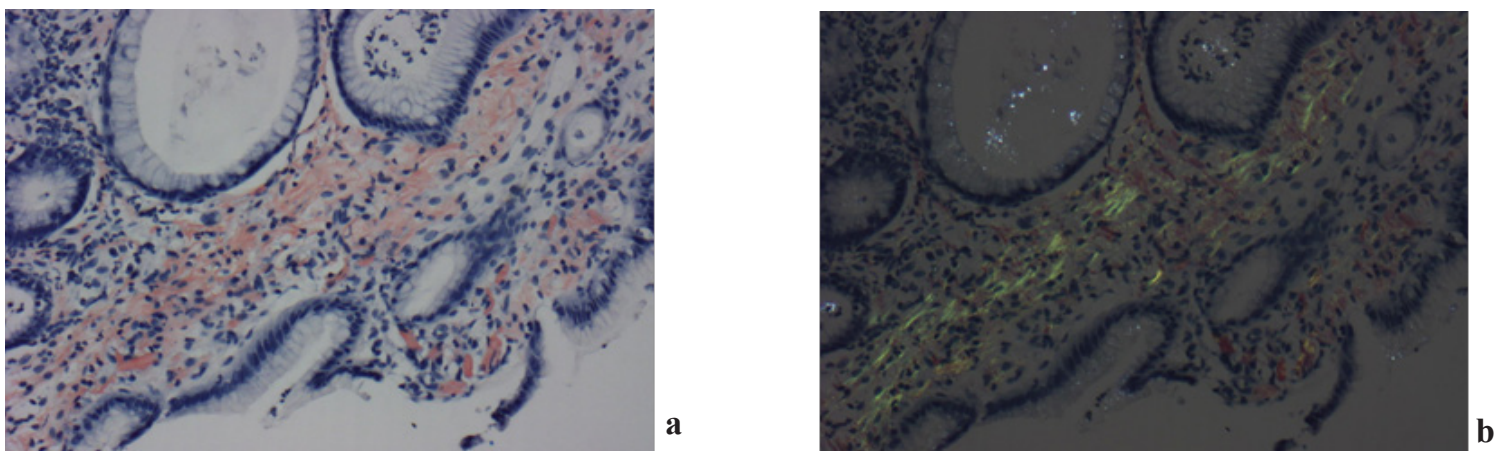

Figure 3. $\mathbf{a}$ and $\mathbf{b}$, histopathology showing duodenal amyloidosis. Figure 3a illustrates amyloid deposition under Congo red staining, and Figure $\mathbf{3 b}$ shows apple-green birefringence under polarized light microscopy. 


\section{Case 3}

A 72-year-old man presented with edema, and was diagnosed with nephrotic syndrome. A renal biopsy confirmed AL $\lambda$ amyloidosis, and evaluation showed no evidence of other organ involvement. The patient was treated with melphalan and autologous stem cell transplantation. Seven years later, he had worsening of his kidney function, and repeat kidney biopsy revealed relapsed amyloidosis. He was treated with bortezomib, without improvement in renal function, and eventually required hemodialysis.

Two years after relapse of amyloidosis, the patient developed recurrent episodes of melena requiring frequent blood transfusions. EGD showed multiple friable and erythematous polypoid protrusions of the gastric and duodenal mucosa with confirmation of amyloid deposition on pathology (Figure 4). Colonoscopy revealed several small tubular adenomas, but otherwise, no obvious source of bleeding. Deep bowel enteroscopy did not reveal an alternative etiology for bleeding. His bleeding was determined to be from diffusely erythematous gastric and duodenal mucosa in the setting of chronic renal failure and thrombocytopenia. Due to frequent melena, he was dependent on blood transfusions several times per week to maintain a hemoglobin level higher than $7 \mathrm{~g} / \mathrm{dL}$. He was treated with aminocaproic acid with mild improvement in bleeding; however ultimately, hospice care was pursued.

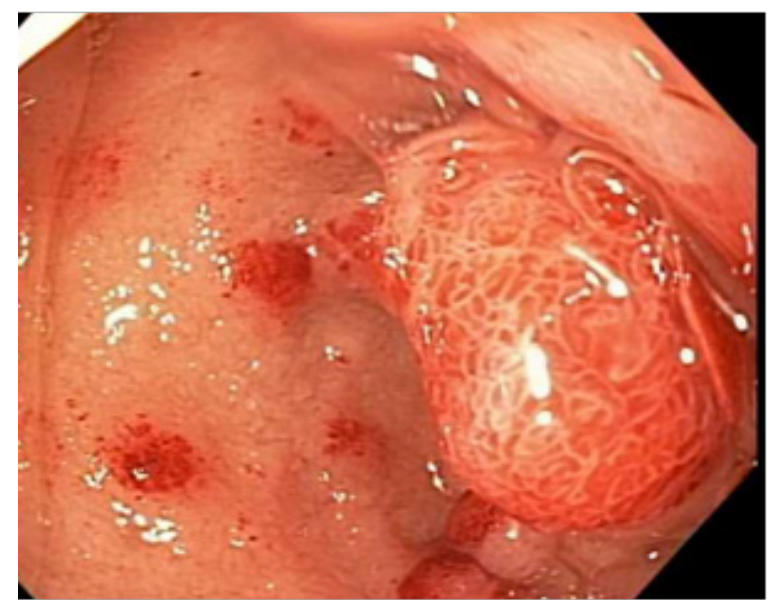

Figure 4. Severe erythematous duodenopathy.

\section{Discussion}

Amyloidosis is characterized by the misfolding of extracellular proteins, called amyloid fibrils, with tissue deposition of insoluble, toxic protein aggregates in the extracellular spaces of organs and tissues $[3,4]$. The four main systemic types include AL amyloidosis; AA, or secondary amyloidosis; familial amyloidosis (ATTR), characterized by mutations in the precursor protein transthyretin; and $\beta 2$-microglobulin amyloidosis associated with end-stage renal disease and dialysis [4]. The amyloid fibrils deposit in tissue as rigid, nonbranching fibrils approximately 10 $\mathrm{nm}$ in diameter [5]. The distinctive appearance of amyloid on polarized light microscopy, and the gold standard for diagnosis, is apple-green birefringence under Congo red staining. Tissue deposition of these proteins causes direct tissue damage and disruption of tissue architecture, leading to organ dysfunction $[3,6]$.

Organs are variably involved depending on the type, with the heart and kidneys most commonly involved in AL amyloidosis, and the heart and nervous system most commonly involved in ATTR [7]. The most common site of GI mucosal infiltration is the second part of the duodenum, followed by the stomach, colorectum, and esophagus [8]. In a single-center retrospective study of 2,334 patients with amyloidosis, 3\% had biopsy-proven GI tract amyloid involvement, of which, $80 \%$ had systemic amyloidosis and $20 \%$ had no other organ involvement.(9) GI symptoms are estimated to occur in up to $60 \%$ of patients with $\mathrm{AL}$ amyloidosis and 70\% with AA amyloidosis [1,2]. Despite the high prevalence of GI symptoms, biopsy-proven GI involvement is less common $(3 \%-7 \%)[6,9]$. Involvement of the GI tract in AL amyloidosis is defined by the presence of GI symptoms and direct biopsy verification [10]. There are no standardized guidelines for diagnosis and staging for the other systemic and localized amyloidoses, and clinicians often define organ involvement per the guidelines for AL amyloidosis.

The presenting symptoms of GI amyloidosis are variable and nonspecific, including weight loss, early satiety, GI bleeding, and abdominal pain. Patients may have malabsorption characterized by diarrhea, steatorrhea, hypoalbuminemia, or other dysmotility-type symptoms, including nausea and heartburn $[9,11,12]$. The clinical signs and symptoms of hepatic amyloidosis are broad, ranging from findings of hepatomegaly and elevated liver function tests to stigmata of portal hypertension and hepatic failure [13]. Within the GI tract, amyloid deposition occurs in the muscularis mucosa close to the nerves and vasculature, leading to increased vessel fragility, decreased peristalsis, decreased compliance of the gut wall, and associated symptoms [14-16].

The endoscopic findings of amyloidosis are variable and may correlate with the clinical symptoms and findings on histopathology. Characteristic endoscopic findings in AL amyloidosis include multiple polypoid protrusions and thickening of the valvulae conniventes. Accordingly, presenting symptoms are constipation or signs of mechanical obstruction or pseudo-obstruction. Additional findings are mucosal erosions, ulcerations, and submucosal hematomas, which may be a distinctive finding for AL amyloid involvement of the GI tract with bleeding [1]. In our case series, the first patient demonstrated colitis with diffuse mucosal ulceration, which improved following repeat autologous stem cell transplantation. The other two patients had polypoid protrusions with friable mucosa. 
Endoscopically, AA amyloidosis presents as a fine granular appearance of the mucosa, with associated symptoms of diarrhea, malabsorption, and GI bleeding [17]. Amyloid deposition is predominantly in the lamina propria [17]. In AL amyloidosis, amyloid deposition is generally found in the outer coat of small- and medium-sized blood vessels, with parenchymal deposition in the muscle layers. In ATTR and AA amyloidosis, amyloid deposition occurs in the inner coat of small blood vessels, and parenchymal deposition occurs primarily in the mucosa [18].

In a retrospective study of 20 patients with symptomatic GI amyloidosis, submucosal infiltration correlated with a granular or thickened mucosa on endoscopy. In patients with infiltration of the lamina propria (mucosa), superficial lesions predominated, including ulcers, erosions, friability, and edema. Although the location of amyloid deposition on pathology correlated with the endoscopic findings, there was no correlation with the specific type of amyloid [19].

The location of involvement along the GI tract and within the gut wall varies among the types of amyloidosis. Overall, AL amyloidosis is the most common form within the GI tract. In a retrospective study of 663 biopsies of the GI tract demonstrating amyloid deposition, mucosal involvement, as compared to submucosal involvement, was more common in $\mathrm{AA}$ and $\mathrm{AL} \kappa$ amyloidosis, less common in AL $\lambda$ amyloidosis, and rare in ATTR amyloidosis. AL $\kappa$ and ATTR amyloidosis were distributed more commonly in the upper GI tract, and AL $\lambda$ and ATTR amyloidosis in the large intestine. Based on these findings, the authors proposed that endoscopists use this information to guide selection of the biopsy site when amyloidosis is suspected [20].

Any amyloid-containing biopsy of the GI tract is suitable for diagnosis of amyloidosis. As the symptoms of amyloidosis are often nonspecific, endoscopists should have a high clinical suspicion when performing endoscopy as diagnosis can be confirmed with pathology. Diagnosis of amyloidosis was confirmed via colonoscopy in Case 2. Biopsy from the GI tract is accessible, and may negate further need for invasive testing, including cardiac or renal biopsy. Pathologic evaluation for amyloidosis with Congo red staining may not be routine practice at all medical centers, which again requires high clinical suspicion.

GI bleeding is rare as the initial presentation or sole manifestation of amyloidosis, and may be obscure, overt, and even life-threatening. Deposition of amyloid causes vascular fragility, which may produce submucosal bleeding and hematoma formation. Endoscopic and surgical treatment of bleeding from GI amyloidosis is difficult given the widespread nature of the disease [23]. Surgical resection of an expanding gastric submucosal hematoma has been reported in the literature [24]. Generally, treatment is directed at the underlying condition. The second part of the duodenum is the most common site of GI amyloid involvement [8]. Capsule endoscopy can be considered for evaluation of patients with a suspected small bowel source of bleeding from amyloid, and negative EGD and colonoscopy [22].

Treatment of amyloidosis is aimed at reducing the production of amyloidogenic protein to prevent further growth of amyloid deposits and organ dysfunction. Early diagnosis is important to start treatment and prevent progression [4]. Treatment of AL amyloidosis is directed at eradicating the underlying plasma cell dyscrasia with chemotherapy. High-dose melphalan and autologous stem cell transplantation has shown survival benefit, despite a high treatment-related mortality of 15\% [25]. Several novel agents, including the proteasome inhibitor, bortezomib, are under evaluation in combination with dexamethasone [26]. Similarly in AA amyloidosis, treatment is aimed at decreasing AA serum levels by suppression or eradication of the underlying inflammatory disease [4]. Currently, the only established treatment of patients with ATTR amyloidosis is liver transplantation, which removes the source of mutated transthyretin from the circulation [27]. Treatment for $\beta 2$ microglobulin amyloidosis is kidney transplantation [4]. Systemic amyloidosis generally has a grave prognosis as most cases are diagnosed late into the disease course with multi-organ dysfunction, limiting therapeutic interventions. Diagnosis is often delayed due to the nonspecific presenting signs and symptoms of this disease, and its insidious progression [1]. Two studies have found the median delay from onset of symptoms to diagnosis was 7 months $[11,12]$. The prognosis of AL amyloidosis is poor, with a reported median survival between 12 and 18 months, depending on severity and number of organs involved [28,29].

Treatment of GI involvement of amyloidosis is directed at management and amelioration of symptoms [2]. It is important to address adequate hydration and nutritional intake, particularly in patients with malabsorption. For disabling dysmotility-related symptoms, total parenteral nutrition can be considered [2]. Treatment with lomotil or loperamide may be helpful in patients with diarrhea, and metoclopramide in patients with early satiety. Antiemetics, such as prochlorperazine, promethazine, and ondansetron hydrochloride, may be helpful in patients with nausea and vomiting [9].

In summary, symptomatic and biopsy-proven GI involvement of amyloidosis is not commonly reported, and has varying clinical and endoscopic presentations. We present a case series of three patients with GI amyloidosis and associated GI bleeding. Common endoscopic findings in GI amyloidosis with bleeding include friable mucosa with ulcerations and submucosal hematomas. Treatment of GI bleeding from amyloidosis is difficult, given the widespread nature of the disease and bleeding. The prognosis of GI amyloidosis is often poor and related to the severity of the underlying illness. 


\section{References}

1. James DG, Zuckerman GR, Sayuk GS, Wang HL, Prakash C. Clinical recognition of Al type amyloidosis of the luminal gastrointestinal tract. Clin Gastroenterol Hepatol. 2007;5(5):582588.

2. Petre S, Shah IA, Gilani N. Review article: gastrointestinal amyloidosis - clinical features, diagnosis and therapy. Aliment Pharmacol Ther. 2008;27(11):1006-1016.

3. Sipe JD, Benson MD, Buxbaum JN, Ikeda SI, Merlini G, Saraiva MJ, et al. Amyloid fibril proteins and amyloidosis: chemical identification and clinical classification International Society of Amyloidosis 2016 Nomenclature Guidelines. Amyloid. 2016;23(4):209-213.

4. Hazenberg BP. Amyloidosis: a clinical overview. Rheum Dis Clin North Am. 2013;39(2):323-345.

5. Sipe JD, Benson MD, Buxbaum JN, Ikeda S, Merlini G, Saraiva MJ, et al. Nomenclature 2014: Amyloid fibril proteins and clinical classification of the amyloidosis. Amyloid. 2014;21(4):221-224.

6. Merlini G, Bellotti V. Molecular mechanisms of amyloidosis. N Engl J Med. 2003;349(6):583-596.

7. Falk RH, Comenzo RL, Skinner M. The systemic amyloidoses. N Engl J Med. 1997;337(13):898-909.

8. Tada S, Iida M, Iwashita A, Matsui T, Fuchigami T, Yamamoto T, et al. Endoscopic and biopsy findings of the upper digestive tract in patients with amyloidosis. Gastrointest Endosc. 1990;36(1):10-14. 9. Cowan AJ, Skinner M, Seldin DC, Berk JL, Lichtenstein DR, O'Hara CJ, et al. Amyloidosis of the gastrointestinal tract: a 13-year, single-center, referral experience. Haematologica. 2013;98(1):141-146.

10. Gertz MA, Comenzo R, Falk RH, Fermand JP, Hazenberg BP, Hawkins PN, et al. Definition of organ involvement and treatment response in immunoglobulin light chain amyloidosis (AL): a consensus opinion from the 10th International Symposium on Amyloid and Amyloidosis, Tours, France, 18-22 April 2004. Am J Hematol. 2005;79(4):319-328.

11. Hayman SR, Lacy MQ, Kyle RA, Gertz MA. Primary systemic amyloidosis: a cause of malabsorption syndrome. Am J Med. 2001;111(7):535-540.

12. Madsen LG, Gimsing P, Schiødt FV. Primary (AL) amyloidosis with gastrointestinal involvement. Scand J Gastroenterol. 2009;44(6):708-711.

13. Sonthalia N, Jain S, Pawar S, Zanwar V, Surude R, Rathi PM. Primary hepatic amyloidosis: A case report and review of literature. World J Hepatol. 2016;8(6):340-344.

14. Kaiserling E, Kröber S. Massive intestinal hemorrhage associated with intestinal amyloidosis. An investigation of underlying pathologic processes. Gen Diagn Pathol. 1995;141(2):147-154.

15. Rowe K, Pankow J, Nehme F, Salyers W. Gastrointestinal Amyloidosis: Review of the Literature. Cureus. 2017 May 8;9(5):e1228. doi: 10.7759/cureus. 1228 .
16. Hirschfield GM. Amyloidosis: a clinico-pathophysiological synopsis. Semin Cell Dev Biol. 2004;15(1):39-44.

17. Tada S, Iida M, Yao T, Kawakubo K, Yao T, Okada M, et al. Endoscopic features in amyloidosis of the small intestine: clinical and morphologic differences between chemical types of amyloid protein. Gastrointest Endosc. 1994;40(1):45-50.

18. Gilat T, Revach M, Sohar E. Deposition of amyloid in the gastrointestinal tract. Gut. 1969;10(2):98-104.

19. Alcalde-Vargas A, Leo-Carnerero E, Rojas-Mercedes N, TrigoSalado C, Herrera-Justiniano JM, Márquez-Galán JL. Correlation between location of amyloid deposits and endoscopic and clinical manifestations in symptomatic gastrointestinal amyloidosis. Rev Esp Enferm Dig. 2015;107(1):49-51.

20. Freudenthaler S, Hegenbart U, Schönland S, Behrens HM, Krüger S, Röcken C. Amyloid in biopsies of the gastrointestinal tract-a retrospective observational study on 542 patients. Virchows Arch. 2016;468(5):569-577.

21. Hokama A, Kishimoto K, Nakamoto M, Kobashigawa C, Hirata T, Kinjo N, et al. Endoscopic and histopathological features of gastrointestinal amyloidosis. World J Gastrointest Endosc. 2011;3(8):157-161.

22. Redondo-Cerezo E, Sánchez-Capilla AD, De La TorreRubio P, De Teresa J. Wireless capsule endoscopy: perspectives beyond gastrointestinal bleeding. World J Gastroenterol. 2014;20(42):15664-15673.

23. Yeh YC, Lin $\mathrm{CH}$, Huang SC, Tsou YK. Education and imaging. Gastrointestinal: gastric hematoma with bleeding in a patient with primary amyloidosis. J Gastroenterol Hepatol. 2014 Mar; 29(3):419.

24. Kim SY, Moon SB, Lee SK, Hong SK, Kim YH, Chae $\mathrm{GB}$, et al. Light-chain amyloidosis presenting with rapidly progressive submucosal hemorrhage of the stomach. Asian $\mathrm{J}$ Surg. 2016;39(2):113-115.

25. Rosengren S, Mellqvist UH, Nahi H, Forsberg K, Lenhoff S, Strömberg O, et al. Outcome of AL amyloidosis after high-dose melphalan and autologous stem cell transplantation in Sweden, long-term results from all patients treated in 1994-2009. Bone Marrow Transplant. 2016;51(12):1569-1572.

26. Desport E, Bridoux F, Sirac C, Delbes S, Bender S, Fernandez B, et al. Al amyloidosis. Orphanet J Rare Dis. 2012 Aug 21;7:54. doi: 10.1186/1750-1172-7-54.

27. Wilczek HE, Larsson M, Ericzon BG, FAPWTR. Long-term data from the Familial Amyloidotic Polyneuropathy World Transplant Registry (FAPWTR). Amyloid. 2011;18 Suppl 1:193-195.

28. Kumar SK, Gertz MA, Lacy MQ, Dingli D, Hayman SR, Buadi FK, et al. Recent improvements in survival in primary systemic amyloidosis and the importance of an early mortality risk score. Mayo Clin Proc. 2011;86(1):12-18.

29. Comenzo RL. Amyloidosis. Curr Treat Options Oncol. 2006;7(3):225-236. 